\title{
AUDITIO: el renovado journal de la Asociación Española de Audiología
}

\author{
Juan García-Valdecasas Bernal \\ Servicio de Otorrinolaringología, Hospital Virgen de los Nieves, Granada, España \\ Presidente de la Asociación Española de Audiología (AEDA)
}

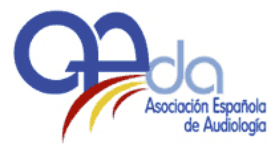

¡AUDITIO se renueva! Llega el Día Mundial de la audición y no podíamos haber elegido mejor momento para dar la bienvenida a la nueva AUDITIO. Tras muchos meses de trabajo, AEDA ha conseguido renovar de manera única su revista científica. Un equipo, liderado el Dr. Raul Sánchez, flamante Editor Jefe de la revista, empezó a trabajar con el objetivo de renovar, modernizar y adaptar la revista a las necesidades del siglo XXI. Puede que les sorprenda pero

AUDITIO es una revista pionera en audiología pues fue diseñada, por la Fundación Canaria Dr. Barajas en 2001, como una revista electrónica de acceso libre. Les aseguro que en 2001 este formato era toda una novedad y este hecho ha marcado su existencia. La distribución de AUDITIO a través de internet entre la

... Un elemento clave en la promoción de la práctica clínica basada en la evidencia científica $y$ el altavoz del conocimiento en audiología en lengua española comunidad hispanohablante la convirtió en la revista de Audiología de mayor difusión en lengua española y por tanto, una de las revistas más leídas. AUDITIO siempre ha mantenido su orientación académica y ha cumplido con éxito

su objetivo: la divulgación gratuita de la Audiología. Entonces, ¿por qué tenía que ser renovada? Era una demanda de nuestros asociados y una espina clavada en muchos de nosotros. Tanto que se convirtió en un objetivo de mi programa de actuación para la legislatura de Presidencia en las elecciones del 2020.

El motivo de esa demanda era claro: su falta de periodicidad. En el último lustro AUDITIO ha sufrido altibajos y la falta de regularidad, por una menor recepción de publicaciones. No ha sido por falta de trabajo de su Editora Jefe, la Dra. Bartolomé, que supo rodearse de un gran equipo de revisores, supo incentivar a los universitarios $y$ manejó con maestría sus contactos con prestigiosos investigadores para mantener la mayor regularidad posible.

Todos debemos agradecerle su esfuerzo, dedicación y resultados, pero AUDITIO enfermaba lentamente y no supimos detectarlo ni fuimos capaces de encontrar soluciones. $Y$ ante la enfermedad, renovar o morir. Era la cruel realidad que AEDA tenía que afrontar. $Y$ tras profundizar en los 
motivos, descubrimos que AUDITIO aún tenía posibilidades y decidimos apostar por ella y marcar un punto de inflexión. AUDITIO y la audiologia en español lo merece. Porque la audiología es una de las disciplinas de la ciencia con mayor producción científica y en ella debemos fundamentar su desarrollo futuro. AUDITIO debe mantener su papel único, como medio de expresión dentro de la audiología en lengua española.

Un elemento clave en la promoción de la práctica clínica basada en la evidencia científica y el altavoz del conocimiento en audiología en lengua española donde publicar nuevas investigaciones, proyectos, guías de la práctica clínica, resúmenes de congresos etc. Un medio de comunicación ágil, joven y dinámico, ajustado al mayor rigor científico. AUDITIO merece la pena y debe tener su espacio en nuestra disciplina y nuestra lengua (la $2^{\mathrm{a}}$ lengua materna más hablada en el mundo). Hoy, Día Mundial de la Audición, empieza una nueva era para AUDITIO. Una revista cuyas publicaciones serán fácilmente localizables por los lectores, una revista moderna, acorde a las necesidades de autores y lectores. Para ello, aspiramos fuerte y adoptamos el sistema Open Journal System (para la gestión de contenido, postulaciones, revisiones y producción), registramos todo el contenido con Digital Object Identifiers (DOI), adecuamos la revista a los estándares de calidad de FECYT y ajustamos los contenidos para una mejor indexación de Google Scholar, RedIB, PubMed, WoS, Scielo, etc. Un nuevo tiempo, un salto de calidad, un objetivo al alcance de esta Junta Directiva, un esfuerzo de los asociados de AEDA y un brillante trabajo, catalizado por su vocal y Director Jefe de la revista, Dr. Raul Sánchez. ¡Enhorabuena a todos!
García-Valdecasas Bernal, J., AUDITIO: el renovado journal de la Asociación Española de Audiología, AUDITIO vol. 5(2) 1-2. https://doig.org/10.51445/sja.auditio.vol5.2021.0064

https://journal.auditio.com

Publicado: 03.04.2021 